\title{
The Role of Hba1c as a Diagnostic Test for Type 2 Diabetes Mellitus in Bangladesh.
}

\author{
Md Matiur Rahman ${ }^{1}$, Naila Atik Khan², Mohammad Masum Alam³, M Iqbal Arslan ${ }^{4}$, Md Golam Hafiz ${ }^{5}$ \\ ${ }^{1}$ Associate Professor, Dept of Biocemestry ${ }^{2}$ Research Assistant, ${ }^{3}$ Research Assistant, ${ }^{4}$ Professor \& Chairman, Department of Biochemistry, ${ }^{5}$ Associate \\ Professor, Department of Paediatric Hematology-Oncology, BSMMU
}

\begin{abstract}
:
Background: Type 2 diabetes mellitus is a serious chronic disease with micro vascular complications such as retinopathy, nephropathy and neuropathy and macro vascular complications such as cardiac, peripheral arterial and cerebrovascular disease. Objective: The aim of the study was to investigate the value of HbAlc as a diagnostic test for type 2 diabetes mellitus in Bangladeshi individuals. Methods: This cross sectional study was conducted in the Department of Biochemistry, Bangabandhu Sheikh Mujib Medical University, Dhaka, Bangladesh. A total 657 patients, who were attended in the one point sample collection centre of Bangabandhu Sheikh Mujib Medical University for oral glucose tolerance test (OGTT) from 1st April 2014 to 30th June 2014, were purposively enrolled in this study. According to WHO criteria and based on OGTT findings study subjects were categorized into Normoglycemic (257), IFG (82), IGT (174), and DM (347). Fasting plasma glucose, HbAlc and plasma glucose at 2 hour after glucose load on OGTT was done from all the study subjects. Results: With a cut-off value of $6.1 \%, \mathrm{HbAlc}$ had a maximal sensitivity and specificity of $97.0 \%$ and $49.0 \%$ respectively with a positive predictive value $65.5 \%$ and a negative predictive value $94.0 \%$. HbAlc had a sensitivity of $93.0 \%$ and a specificity of $63.0 \%$ was calculated with a cut-off value of $6.5 \%$ with positive predictive value $77.5 \%$ and negative predictive value $90.0 \%$. Both fasting plasma glucose levels and 2 hour plasma glucose levels were showed significant positive correlation with $\mathrm{HbAlc}(\mathrm{r}=0.788, \mathrm{P}=0.000$ and $\mathrm{r}=0.800, \mathrm{P}=0.000$ respectively). Conclusion: The study suggests that measurement of HbAlc could be used to make diagnosis of T2DM in the Bangladeshi population.
\end{abstract}

Key words: HbAlc, Type 2 diabetes mellitus, diagnosis, oral glucose tolerance test.

[BSMMU J $2014 ; 7$ (2) : 115-119]

\section{Introduction:}

The term diabetes mellitus (DM) describes a metabolic disorder with heterogeneous aetiologies which is characterized by chronic hyperglycemia and disturbances of carbohydrate, fat and protein metabolism resulting from defects in insulin secretion, insulin action, or both ${ }^{1}$. The long term relatively specific effects of diabetes include development of retinopathy, nephropathy and neuropathy ${ }^{2}$. People with diabetes are also at increased risk of cardiac, peripheral arterial and cerebrovascular disease $^{3}$. Rates of T2DM have increased markedly since

Address for Correspondence: Md Matiur Rahman, Associate Professor Department of Biochemistry, Bangabandhu Sheikh Mujib Medical University.
1960 in parallel with obesity. As of 2010 there were approximately 285 million people diagnosed with the disease compared to around 30 million in $1985^{4,5}$. By 2030 , the worldwide prevalence of adult DM is expected to rise to $7.7 \%$, which roughly translates to 439 million affected individual ${ }^{6}$. In 2010, the International Diabetes Federation estimated that 5.7 million $(6.1 \%)$ and 6.7 million $(7.1 \%)$ of people living in Bangladesh is suffering from diabetes and impaired glucose tolerance (IGT) respectively. By 2030, that number of diabetic population is expected to rise to 11.1 million. This explosion on diabetes prevalence will place Bangladesh among the top seven countries in terms of the number of people living with diabetes in $2030^{7}$. 
Based on current recommendations, diagnosis of DM requires the presence of a fasting plasma glucose concentration of $\geq 7.1 \mathrm{mmol} / \mathrm{L}$, or a 2 hour plasma glucose level of $\geq 11.1 \mathrm{mmol} / \mathrm{L}$ on an oral glucose tolerance test (OGTT). On the other hand, international committee members selected by the American Diabetes Association (ADA) and the Alliance for European Diabetes Research (EURADIA) recently suggested that glycosylated hemoglobin (HbAlc) could be used as an alternative for making diagnosis of $\mathrm{DM}^{8}$. The committee concluded that an $\mathrm{HbA1c}$ level of $\geq 6.5 \%$ was diagnostic for $\mathrm{DM}$, without requiring a determination of plasma glucose levels. However, the use of standard glucose measurements is still recommended for individuals when $\mathrm{HbAlc}$ assays are deemed unreliable? .

HbAlc is formed as a result of the addition of a stable glucose molecule to the $\mathrm{N}$-terminal group of an $\mathrm{HbA0}$ molecule via a non enzymatic glycation process ${ }^{10}$, and is considered a reliable indicator of the glycemic status of the previous 3 months ${ }^{11}$.

Despite the cloud of controversy regarding the limitations of HbAlc for making diagnosis of DM, many experts believe that HbAlc may be superior to the OGTT in daily clinical practice as there was no need of preparation of patient, no fasting is necessary, sample collection and test procedure is simple, there was no variation of test result like plasma glucose ${ }^{12}$.

The aim of this study was to investigate the value of $\mathrm{HbAlc}$ as a diagnostic test for T2DM in Bangladeshi individuals.

\section{Methods :}

This cross sectional study was undertaken in the Department of Biochemistry, Bangabandhu Sheikh Mujib Medical University, Dhaka, Bangladesh. Patients, who were attended in the one point sample collection centre of Bangabandhu Sheikh Mujib Medical University for oral glucose tolerance test (OGTT) from 1st April 2014 to 30th
June 2014, were purposively enrolled in this study.

From each patient, blood samples were obtained at 0800 hours and onward following 10 hours fast, from the antecubital vein in a sitting position, for the determination of $\mathrm{HbAlc}$ as well as fasting plasma glucose level. All patients were then subjected to a 75-gm OGTT on the same day, and second blood samples were obtained 2 hour after glucose loading for determination of plasma glucose level. For determination of HbA1c whole blood samples were collected in vacuum tube contains EDTA and for plasma glucose measurement blood samples were collected in fluoride tube.

An NGSP-approved for the percent determination of $\mathrm{HbAlc}$ in human whole blood using ion-exchange highperformance liquid chromatography (HPLC) method on a D-10 Hemoglobin A1c program (Bio-Rad, Japan) analyzer. Blood samples were automatically diluted on the D-10 and injected in the analytical cartridge. The D-10 delivers a programmed buffer gradient of increasing ionic strength into the analytical cartridge, where the hemoglobin is separated base on their ionic interactions with the cartridge material. The separated hemoglobin then passes through the flow cell of the photometer, where changes in absorbance at $415 \mathrm{~nm}$ were measured. Glucose measurements were made on the same day as HbAlc measurements, using the glucose oxidation method on Dead Behring (Bio-Rad, Japan) auto analyzer. Subjects were categorized into 4 groups based on their OGTT results, according to the criteria put forth by the WHO: normoglycemic (NG), impaired fasting glucose (IFG), impaired glucose tolerance (IGT), and diabetes mellitus (DM).

Statistical analyses were performed using SPSS windows version 20. Values for HbA1c and plasma glucose levels were provided as mean \pm standard deviation. The sensitivity, specificity, positive predictive values, and negative predictive values for both tests were calculated by plotting a receiver operating characteristic (ROC) curve. Correla- 
tion analyses between fasting plasma glucose, 2 hour plasma glucose, and HbA1c levels were performed using Spearman's correlation test. A p-value of less than 0.05 was considered indicative of statistical significance.

\section{Results:}

A total of 657 consenting participants (360 male and 297 female) were included in this study. Based on OGTT results and according to criteria put forth by the WHO, 257 individuals were categorized as normoglycemic, 82 were IFG, 174 were IGT and 347 were DM. The demographic characteristics and laboratory findings of the study population have been summarized in the Table.

\section{Table-I}

Demographic and Laboratory findings of study population

\begin{tabular}{llcccc}
\hline \multicolumn{1}{c}{ Parameters } & Total $(\mathrm{N}=657)$ & $\mathrm{NG}$ & IFG & IGT & D M \\
Age $(\mathrm{Y}$ ears $)$ & $47.88 \pm 11.33$ & & & \\
Sex $(\mathrm{M}, \mathrm{F})$ & 360,297 & & & \\
FPG (m m olL) & $7.87 \pm 3.42$ & $5.08 \pm 0.57$ & $6.43 \pm 0.29$ & & $10.50 \pm 3.18$ \\
& & $(\mathrm{~N}=257)$ & $(\mathrm{N}=82)$ & & $(\mathrm{N}=218)$ \\
2 h PG (m m olL $)$ & $12.56 \pm 5.33$ & $6.64 \pm 0.75$ & & $9.30 \pm 0.98$ & $16.52 \pm 4.28$ \\
& & $(\mathrm{~N}=136)$ & & $(\mathrm{N}=174)$ & $(\mathrm{N}=347)$ \\
HbA 1c $(\%)$ & $8.08 \pm 2.36$ & & & \\
\hline
\end{tabular}

$\mathrm{NG}=$ normoglycemic IFG= Impaired fasting gluease IGT =Impained glucose to leramee DM=Diabe tesmellitng

Values provided as mean \pm standard deviation; HbAlcglycosylated hemoglobin; NG- normoglycemic group; IFG- impaired fasting glucose group; IGT- impaired glucose tolerance group; and DM- diabetes mellitus group.

The OGTT was considered the gold-standard test for the diagnosis of DM. The area under the ROC curve for the diagnosis of DM by HbAlc was $0.90(\mathrm{P}<0.001)$ (Figure 1). With a cut-off value of $6.1 \%, \mathrm{HbA} 1 \mathrm{c}$ had a maximal sensitivity and specificity of $97.0 \%$ and $49.0 \%$ respectively with a positive predictive value $65.5 \%$ and negative predictive value $94.0 \%$. With a cut-off value of $6.5 \%$, $\mathrm{HbAlc}$ had a sensitivity of $93.0 \%$ and a specificity of $63.0 \%$ respectively with positive predictive value $77.5 \%$ and negative predictive value $90.0 \%$.

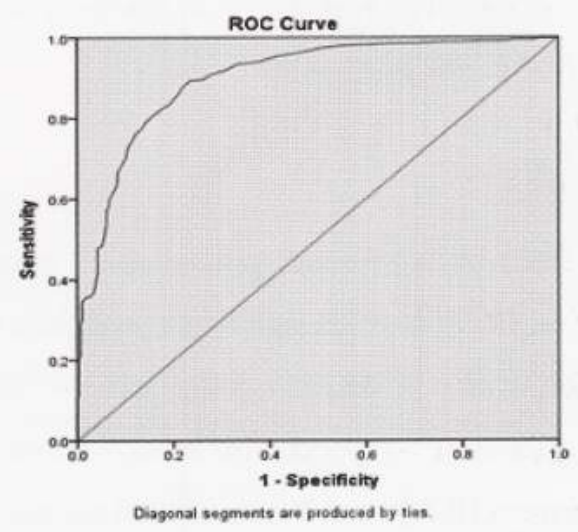

Fig-1: Receiver operating characteristic curve for $\mathrm{HbAlc}$ in patient with diabetes mellitus.

A significant positive correlation was observed between $\mathrm{HbAlc}$, fasting plasma glucose $(\mathrm{r}=0.788, \mathrm{P}=0.000)$, and $2 \mathrm{~h}$ plasma glucose $(\mathrm{r}=0.800, \mathrm{P}=0.000)$ levels in patients with DM (Figures $2 \& 3$ ). 


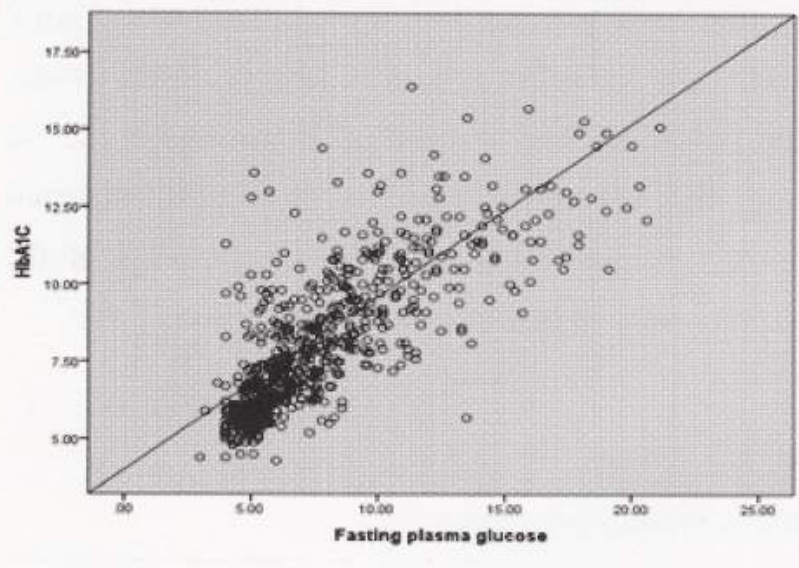

Fig-2: Correlation curve for fasting plasma glucose and HbAlc $(r=0.788, p=0.000)$.

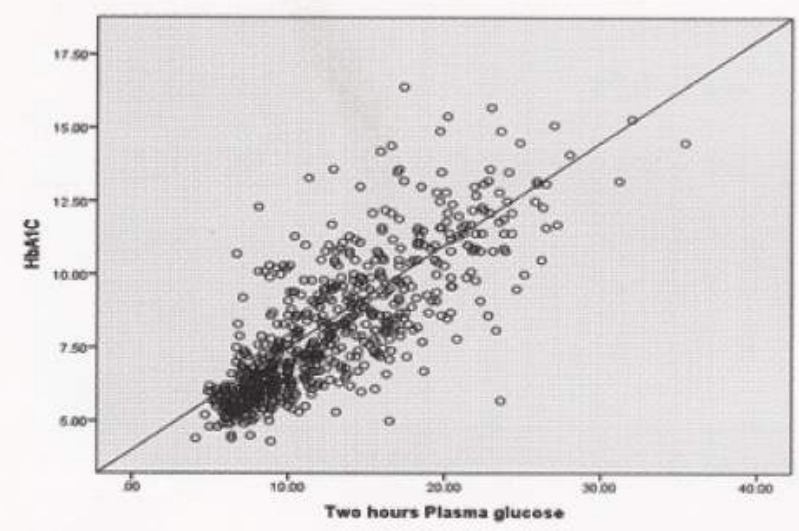

Fig-3: Correlation curve for $2 \mathrm{~h}$ plasma glucose and HbAlc $(r=0.800, p=0.000)$.

\section{Discussion:}

In this study fasting plasma glucose and 2 hour plasma glucose on OGTT showed significant positive correlation with HbAlc $(r=0.788, p=0.000$ and $r=0.800, p=$ 0.000 ). Riet et al. ${ }^{13}$ reported that weak positive correlations between $\mathrm{HbAlc}$ and fasting plasma glucose levels ( $\mathrm{r}$ $=0.46)$, as well as 2 hour plasma glucose $(\mathrm{r}=0.33)$ levels, were observed in individuals from the general population. Ginis et al. ${ }^{14}$ reported that both fasting plasma glucose and $2 \mathrm{~h}$ plasma glucose levels were found to correlate moderately with $\mathrm{HbA1c}$ levels $(\mathrm{r}=0.47, \mathrm{P}=0.001$ and $\mathrm{r}=0.52$, $\mathrm{P}=0.000$, respectively) and were consisted with our observations.
Several studies have investigated the value of $\mathrm{HbAlc}$ for the diagnosis of DM with a cut-off level of $6.1 \%$. In such a study by Tavintharan et al. ${ }^{15}$ a sensitivity of $81 \%$ was reported with a specificity of $84 \%$. Similarly, Ko et al. ${ }^{16}$ reported on a sensitivity and specificity of $77.5 \%$ and $78.8 \%$, respectively. With a cut-off value for the diagnosis of DM of $6.1 \%, \mathrm{HbA} 1 \mathrm{c}$ had a sensitivity of $81.8 \%$ and a specificity of $80 \%$, with positive and negative predictive values of $80.2 \%$ and $81.05 \%$, respectively showed by Ginis et al. ${ }^{14}$. Comparable results were observed in our study for diagnosis of DM by HbAlc with a cut-off value of $6.1 \%$ with sensitivity $97 \%$, specificity $49 \%$, with positive predictive value $65.5 \%$ and negative predictive value $94.0 \%$.

Kumar et al. ${ }^{17}$ reported on a sensitivity of $65 \%$ and a specificity of $88 \%$ with positive and negative predictive values of $75.2 \%$ and $96.5 \%$ respectively for diagnosis of DM by HbA1c with a cut-off value of $6.5 \%$. Similar study done by Ginis el al. ${ }^{14}$ also reported that a sensitivity of $56.8 \%$ and a specificity of $89.2 \%$ for diagnosis DM with a cut-off value of $6.5 \%$. In our study with a cut-off value of $6.5 \%, \mathrm{HbAlc}$ had a sensitivity of $93.0 \%$ and a specificity of $63.0 \%$ with positive predictive value $77.5 \%$ and negative predictive value $90.0 \%$.

$\mathrm{HbAlc}$ reflects average plasma glucose over the previous eight to 12 weeks $^{18}$. It can be performed at any time of the day and does not require any special preparation such as fasting. These properties have made it the preferred test for assessing glycemic control in people with diabetes. More recently, there has been substantial interest in using it as a diagnostic test for diabetes and as a screening test for persons at high risk of diabetes ${ }^{19}$. Owing in large part to levels or performing an OGTT, and day-to-day variability in glucose, an alternative to glucose measurements for the diagnosis of diabetes has long been sought. $\mathrm{HbAlc}$ has now been recommended by an International 
Committee and by the ADA as a means to diagnose diabetes $^{19}$.

For diagnosis of DM by measurement of $\mathrm{HbAlc}$ alternate to the OGTT as a reliable test would require the determination of an optimal cut-off value and further studies on a larger scale are required in order to validate $\mathrm{HbA1c}$ assays as a reliable diagnostic test for DM and as a screening test for persons at high risk of diabetes in Bangladeshi individuals.

\section{Conclusion:}

It was concluded from this study that measurement of $\mathrm{HbAlc}$ could be used to make diagnosis of T2DM in the Bangladeshi population.

\section{References:}

1. World Health Organization. Definition, Diagnosis, and Classification of Diabetes Mellitus and its Complications. Part 1: Diagnosis and Classification of Diabetes Mellitus. WHO/NCN/NCS/99.2 ed. Geneva, World Health Organization 1999.

2. Hanssen KF, Bangstad HJ, Brinchmann-Hansen O. Blood glucose control and diabetic microvascular complications: long-term effects of near-normoglycemia. Diabet Med 1992; 9: 697-705.

3. Fox CS, Coady S, Sorlie PD. Increasing cardiovascular disease burden due to diabetic mellitus: The Framingham Heart Study. Circulation 2007; 115: 1544-1550.

4. Williams textbook of endocrinology. 12th ed. Philadelphia: Elsevier/Saunders. 1371-1435.

5. Smyth S, Heron A. Diabetes and obesity: the twin epidemics. Nature Medicine 2006; 12: 75-80.

6. Shaw JE, Sicree RA, Zimmet PZ. Global estimates of the prevalence of diabetes for 2010 and 2030. Diabetes Res Clin Pract 2010; 87: 4-14.

7. Wild S, Roglic G, Green A, Sicree R, King H. Global preva-lence of diabetes: estimates for the year 2000 and projections for 2030 . Diabetes Care 2004; 27: 1047-1053.

8. International Expert Committee report on the role of the A1C assay in the diagnosis of diabetes. Diabetes Care 2009; 32: $1327-34$.

9. Kilpatrick ES, Bloomgarden ZT, Zimmet PZ. Is haemoglobin Alc a step forward for diagnosing diabetes? BMJ 2009; 339: b4432.

10. Jeppsson JO, Kobold U, Barr J, Finke A, Hoelzel W, Hoshino T et al. Approved IFCC reference method for the measurement of HbAlc in human blood. Clin Chem Lab Med 2002; 40: 78-89.

11. Nathan DM, Kuenen J, Borg R, Zheng H, Schoenfeld D, Heine RJ. Translating the A1 assay into estimated average glucose values. Diabetes Care 2008; 31: 1473-8.

12. Arslan M, Atmaca A, Ayvaz G, Başkal N, Beyhan Z, Bolu E et al. The Society of Endocrinology and Metabolism of Turkey, diabetes mellitus and complications diagnosis, treatment and follow-up guide. Ankara: Society of Endocrinology and Metabolism of Turkey 2009.

13. Riet VE, Alssema M, Rijkelijkhuizen JM, Kostense PJ, Nijpels G, Dekker JM. Relationship between AlC and glucose levels in the general Dutch population: the new Hoorn study. Diabetes Care 2010; 33: 61-6.

14. Ginis Z, Ozturk G, Simali R, Yalcinag A, Dulgenoglu V, Delibasi $\mathrm{T}$ and Delibas $\mathrm{N}$. The role of HbAlc as a screening and diagnostic test for Diabetes Mellitus in Ankara. Turk J Med Sci 2012; 42: 1430-1436.

15. Tavintharan S, Chew LS, Heng DM. A rational alternative for the diagnosis of diabetes mellitus in high risk individuals. Ann Acad Med Singapore 2000; 29: 213-8.

16. Ko GT, Chan JC, Yeung VT, Chow CC, Tsang LW, Li JK et al. Combined use of a fasting plasma glucose concentration and $\mathrm{HbAlc}$ or fructosamine predicts the likelihood of having diabetes in high-risk subjects. Diabetes Care 1998; 21: 1221-5.

17. Kumar PR, Bhansali A, Ravikiran M, Bhansali S, Dutta P, Thakur JS et al. Utility of glycated hemoglobin in diagnosing type 2 diabetes mellitus: a community-based study. J Clin Endocrinol Metab 2010; 95: 2832-5.

18. Nathan DM, Tungeon H, Regan S. Relation between Glycated haemoglobin levels and mean glucose levels over time. Diabetologia 2007; 50: 2239-2244.

19. International Expert Committee report on the role of the A1c assay in the diagnosis of diabetes. Diabetes care 2009; 32: 1327-1334. 